\title{
THE DEPARTMENT OF ENERGY'S END-USE CONSERVATION PROGRAM: DISCUSSION PAPER
}

\author{
Marc Ross \\ Department of Physics \\ University of Michigan \\ Ann Arbor, Michigan 48109
}

I am not a student of ERDA* or the Department of Energy, but I know that two years ago ERDA had very limited goals for conservation. It envisioned little medium-term and no long-term conservation R\&D. Of course, anyone can appreciate the reluctance of an organization with the history going from AEC to ERDA to DOE to be enthusiastic about conservation. I suggest that we all must be skeptical and demanding of the Department with respect to conservation, and that is the spirit of my remarks.

\section{Goals for Improved Performance of Energy Technology}

It is important for design and execution of a research, development, and demonstration (RD\&D) program for conservation that (1) the goals be ambitious, (2) the great potential of new technologies be recognized, (3) small-scale and diverse technologies be encouraged, and (4) that systems cutting across bureaucratic lines be considered.

I want to emphasize ambitious goals and the power of new technology in my remarks. I will proceed by sector.

\section{Transportation}

The Volkswagen diesel Rabbit now being sold is rated by EPA to consume gasoline at one-third the present United States fleet average. A turbocharged diesel modified Rabbit has been designed and built that is expected to have an average mileage of $60 \mathrm{mpg}$, a consumption of about one-quarter the present United States average. This modified vehicle is expected to be in production in three years. There is no reason why in the year 2000 this performance standard could not be typical of cars in use. At the same time there is no reason why this particular design should be typical. There is every reason to expect other, but different, favorable technical developments. I see the fuel consumption per mile improvement factor, 0.25 times 1975 performance, as a guide to the least that can and should be attainable.

But what are the ERDA goals? Let us examine the projected demand for gasoline for automobiles in TABLE 2 of Mr. Murray's paper.' Mr. Murray projects an improvement to 0.50 times 1975 auto performance. A factor of one-half is not close to the best known available performance, nor close to what we can realistically expect from technical development. The projection of energy use involves two factors: the technical performance just under discussion and the level of activity (i.e., vehicle miles). Mr. Murray indulges in the practice of exaggerating the level of activity in order to project a high level of energy use. His projection of automobile vehicle miles involves growth by a factor of 2.1 from 1975 to 2000 . Of eight studies on this topic that were recently surveyed ${ }^{2}$ only one estimate is as high as this, and most of the

- Energy Research and Development Administration. 
other estimates are substantially lower-down to two studies that project an increase by a factor of 1.3. We must recognize the fact of saturation. There is a limit, for example, to the amount of time people will spend in their cars.

\section{Buildings}

Recently a researcher at Princeton cleverly modified an already insulated townhouse at a cost of about $\$ 1000$, reducing the fuel needed for heating to one-third of its previous value. ${ }^{3}$ Improvements are much easier to make with new construction or retrofitting buildings not yet insulated. Innovative designs abound to improve thermal performance. Many schemes are also under development for determining the performance of buildings so that standards could be set, consumers would get what they pay for, and designers and builders would get feedback. The improvement goals projected for buildings by the Department of Energy (TABle 2 of Murray's paper) are much too low.

\section{Industry}

It is not feasible to develop a comprehensive analysis of industrial fuel conservation opportunities before the fact. One can examine particular plants and processes and observe that there are a number of overlapping opportunities: good housekeeping, improvement in general energy-conversion devices, process change, and product change (e.g., designing products to enhance recycling or durability characteristics). Let me consider one example from the second category: Industrial process-steam and the generation of electricity now consume some $\mathbf{4 0}$ percent of United States fuel, over 30 quads. Quite in addition to other savings, "cascading" these two functions, i.e., combining production of electricity and steam, offers some 25 percent fuel savings over dual (separate) production. Technical development is the key to exploiting this conservation resource. RD\&D is needed to put in the market small and moderately sized coal and residue burning gas turbines plus waste heat boiler and combined cycle cogeneration systems. These systems would have the advantages of high electricity-to-steam ratios, so that absolute fuel savings are large and of potentially low cost compared to that of new central power stations. Among more remote technologies deserving research are fuel cells and coal-fired diesels.

One ERDA estimate for fuel savings by the year 2000 associated with new industrial cogeneration is very significant: 2.5 quads. I believe the potential by that time is somewhat larger, but my main point is that a variety of institutional and technical factors need RD\&D to properly realize this potential. Without this work the potential is smaller; and indeed the Department of Energy is reportedly being advised by Resource Planning Associates that the potential is, in fact, very small. A high potential is associated with (1) the use of advanced technology and (2) appropriate institutional change, e.g., requiring utilities to build, own and operate industrial cogeneration facilities so that cogeneration economics are evaluated in the context of long-run marginal costs of electricity. The Department of Energy should be putting a major effort into these problems and bringing the attention of policymakers to institutional problems. Cogeneration is only an example. Rewarding research opportunities and challenging policy-making possibilities exist in other areas of industrial energy use.

\section{Estimates of Fuel Savings}

I must also express skepticism about other aspects of calculations by ERDA like the one reported by Mr. Murray. I mention three points: (1) The growth in economic activity is typically based on past aggregate trends for the nation. We believe that it 
would be wiser to consider growth in per capita terms because of the tremendous demographic changes that are occurring.' Thus, for example, past trends in growth of industrial activity per number of the labor force can be examined to make an estimate in that sector. (2) Saturation in per capita demand is, of course, a real phenomenon that brings to an end the growth trend characterizing a product in its earlier stages. The onset of saturation and rough limits to demand can be estimated rather than assuming indefinite continuation of growth rates. Earlier in this paper I discussed ERDA's neglect of this consideration in connection with automobiles. (3) The growth in the price of electricity tends to be underestimated in ERDA studies. (Presumably there is a long-standing ERDA bias on this topic, which people in The Department of Energy's conservation and solar policy and applications offices should work hard to eliminate). We believes that the price of electricity will grow 2 percent or more a year in the rest of this century (in real terms, i.e., after correcting for inflation). The 2 percent growth figures would simply bring the present average cost up to the present long-run marginal cost of electricity.

The upshot of these points is that ERDA projections have tended to overestimate growth of energy demand and the growth of electrification.

\section{Conclusions}

To summarize the first section of my discussion, ERDA, now the Department of Energy is not ambitious or even realistic in its conservation goals. However, ERDA/ DOE is very ambitious in its goals for new energy supply, and often too optimistic in terms of new capital that has to be created in a short time. But they are not ambitious for conservation.

I am not sure how this reluctance can be overcome. Consider the following: Suppose that a realistic projection of growth and conservation goals showed that the nation would probably avoid a supply crunch primarily through new conservation initiatives. Indeed, some studies suggest that the effects of price and of moderately aggressive policy initiatives supporting conservation (such as the type proposed by the President) would control the level of energy use. Energy use might be kept at or below its present value in the period around the turn of the century, and this in conjunction with a healthy economy. Why hasn't ERDA/DOE considered this possibility? I suspect the answer to be that the organization feels threatened by such a possibility. And if this is true, what a strange world this is. Surely (1) the United States needs policy flexibility; (2) we don't really believe that any projections are dependable; (3) the United States may have a hard time maintaining domestic fluid fuel supplies at projected levels; and (4) the United States will need new supplies past the turn of the century. Need I go on? Surely the Department of Energy can find the means to continue to be enthusiastic about its supply RD\&D and still have an office of conservation that is ambitious in its goals.

\section{SOLAR ENERGY RD\&D}

I want to make a remark concerning the Department of Energy's combination of solar research and conservation in the same office. I also want to recommend the excellent series of articles by Allen Hammond and William Metz last summer in Science. They describe the present solar research program, the problems with it, and the opportunities for improvement.

A reason why combining solar research and conservation in one office could prove valuable is that solar energy systems ought to be designed with an appreciation for conservation technologies: Energy from solar sources would be used very differently from the ways energy from oil and gas has been used in the past. The cost 
structure and physical character of the sources would be quite different with solar energy. Studies of energy conservation R\&D will be very useful in providing realistic information about the structure of demand for the design of solar energy systems.

\section{RD\&D MANAGEMENT}

Finally, I will briefly list directions that the DOE units concerned with conservation and solar energy should pursue in research management. I am sure that they have heard these suggestions elsewhere and that many are being acted on.

1. Openness to outside initiative: Research should not be managed in detail from Washington. Chaos now exists in much research because of the rapid fluctuations in the Washington of fice's concerns. This situation is practically a scandal and should be expeditiously resolved. The oscillations in Washington may not be easily damped, so the solution is to be found in loosening the strings. Research, even on so practical a question as commercialization, requires providing research workers with independence and time.

2. The question of scale: Preconceptions about the proper scale of technology should be thoroughly re-examined. Bureaucratically viable means should be found to support small-scale research efforts as well as small-scale technologies. So much of the big-scale aerospace type of research effort is ill-conceived, even if the bureaucracy is well protected by the procedures being used. Perhaps we can find ways to let the university scientist and engineer and the small entrepreneur get into the act and then evaluate their contribution carefully after some work has been done.

3. Economic evaluation: Conservation concepts must, of course, be evaluated economically at the appropriate stage. Realistically high long-run marginal costs of supply should be used for guidance. Again, please develop ambition for conservation and optimism about possibilities for technical and institutional change.

4. Openness to cross-divisional energy systems: Here I refer to ERDA's bureaucratic divisions.

5. Support of basic research: Let us give a really big push to end-use efficiency in the longer term by strong support of basic research.

In conclusion, long-term as well as short-term R\&D is important for conservation. Mr. Murray mentioned that his calculations considered implementation of every single energy conservation device known. I didn't agree with his numbers. But, more important, note that we should not restrict ourselves to every single device known today.

\section{REFERENCES}

1. Murray, G.R. \& J.M. Power. End-Use Technology: The Next Twenty-Five Years. Office of Conservation Planning and Policy, ERDA, March 1977.

2. ShonkA, D.B., A.S. Loebl \& P.D. PATterson. Transportation Energy Conservation Data Book: Edition 2.: Figure 3-11. Oak Ridge National Laboratory, ORNL-5320, October 1977.

3. SINDEN, F. W. Center for Environmental Studies, Report 56, September 1977.

4. MannellA, G.C. Testimony before a subcommittee of the House Committee on Science and Technology, April 4, 1977.

5. Ross, M.H. \& R.H. Whliams. Energy and economic growth. In Achieving The Goals of The Employment Act of 1946 - Thirtieth Anniversary, Energy - Volume 2 (a study prepared for the Joint Economics Committee, Congress of The United States, August 1977). 